Bulletin d'Histoire Contemporaine de l'Espagne

$51 \mid 2017$

Les forces politiques durant la Seconde République espagnole

\title{
El catalanismo durante la Segunda República
} (1931-1939)

catalanismo, Segunda República, Guerra Civil española (1936-1939)

Le catalanisme pendant la Seconde République (1931-1939)

The catalanisme during the Second Republic (1931-1939)

Jordi Casassas Ymbert

\section{(2) OpenEdition}

Journals

Edición electrónica

URL: http://journals.openedition.org/bhce/705

DOI: $10.4000 /$ bhce.705

ISSN: 1968-3723

Editor

Presses Universitaires de Provence

Edición impresa

Fecha de publicación: 1 junio 2017

Paginación: 119-133

ISSN: 0987-4135

Referencia electrónica

Jordi Casassas Ymbert, « El catalanismo durante la Segunda República (1931-1939) », Bulletin

d'Histoire Contemporaine de l'Espagne [En línea], 51 | 2017, Publicado el 09 octubre 2018, consultado el 19 abril 2019. URL : http://journals.openedition.org/bhce/705 ; DOI : 10.4000/bhce.705 


\section{El catalanismo durante la Segunda República (1931-1939)}

\section{Jordi CASASSAS YMBERT}

Universitat de Barcelona

$\mathrm{E}$

1 catalanismo constituye, a un mismo tiempo, un sentimiento (previsiblemente masificado a través de los procesos de nacionalización a medida que avanza el período contemporáneo) y una acción, con una tendencia natural a la politización, que pone a la nación en el centro de los intereses colectivos. En este doble sentido podemos afirmar que el catalanismo llegó a los años de la Segunda República con un grado de madurez considerable a pesar de no disponer de la estructura de un Estado propio para canalizar el doble proceso de la politización moderna y de nacionalización de las masas.

Existían diversos factores que estimulaban esta maduración y que convertía al nacionalismo catalán en un caso destacado y temprano dentro del panorama europeo de los nacionalismos reivindicativos ${ }^{1}$. Sin ánimo de profundizar en su análisis sí que debemos destacar, entre estos factores: la existencia, como mínimo desde el siglo XVIII, de una estructura económica diferenciada y que promociona una integración territorial moderna ${ }^{2}$; la presencia de unos movimientos sociales durante la primera mitad del ochocientos con un componente de clara reivindicación anti centralista (federalismo, carlismo) según han destacado Termes, Seco, Joan Camps y Anguera; la existencia de un importante sector intelectual-profesional que se identifica con el movimiento romántico de la Renaixença $a^{3}$; la relevancia de una corriente regionalista conservadora con voluntad de presión ante el poder central desde la década de 1860; la estructuración de un rico entramado de sociedad civil desde el inicio de la Restauración; la presencia de teorizadores del «hecho catalán» y de estrategias particulares para su defensa y promoción de distinto signo político e ideológico (Almirall, Torras i Bages, Sebastià Farnés, etc.); presencia electoral ininterrumpida desde 1901 y con una «oferta» rica y bien diferenciada, aunque a menudo muy atomizada ${ }^{4}$; acción nacionalizadora del organismo supra provincial, Mancomunitat de Catalunya ${ }^{5}$; capacidad de resistencia a las agresiones externas, especialmente de la Dictadura de Primo de Rivera, por la coexistencia de la acción política y de la sociedad civil ${ }^{6}$.

1 Antoni Rovira i Virgll, Resum d'història del catalanisme, Barcelona, 1936 (1983), y Josep TERmes, (Nou) resum d'història del catalanisme, Barcelona, 2009, y Història del catalanisme fins el 1923,Barcelona, 2000.

2 Pierre VILAR, Catalunya dins l'Espanya moderna. Recerques sobre els fonaments econòmics de les estructures nacionals, Vol.I: Introducció. El medi natural, Barcelona, 1964.

3 J. CASASSAS (coord..), Els intel lectuals i el poder a Catalunya (1808-1975), Barcelona, 1999.

4 Isidre Molas, El sistema de partits politics a Catalunya, Barcelona, 1972 y Idem, ed., Diccionari dels partits politics de Catalunya.Segle XX, Barcelona, 2000.

5 A.Rovira i VIRGLI, La nacionalització de Catalunya. Debats sobre catalanisme, Barcelona, 1914.

6 J.M. Rorg i Rosich, La dictadura de Primo de Rivera a Catalunya. Un assaig de repressió cultural, Barcelona, 1992. 
Claro está que existían al mismo tiempo elementos internos de debilidad que ayudaban a limitar, desde el interior de la propia Catalunya, la consolidación, promoción y éxito de este catalanismo. Podemos citar cuatro: el problema demográfico derivado de ser una área de industrialización con unos índices «franceses» de baja natalidad desde el ochocientos, de basarse por tanto en una constante inmigración (de la montaña y la periferia catalana hasta la inmigración de murcianos «charnegos» de los años veinte) con los consiguientes problemas para fijar una identidad nacional diferenciada ${ }^{7}$; el efecto radicalizador derivado de las características del proceso de industrialización fundamentalmente desregularizado, de erosión constante del mundo rural y la persistencia de altos índices de violencia moderna, con lo que muy a menudo se hará realmente difícil compaginar la emancipación social con la nacional; las dudas de la burguesía autóctona, especialmente a partir de la Gran Guerra, sobre si apoyar a la Monarquía como elemento de seguridad y paz social o embarcarse en la aventura desestabilizadora del nacionalismo reivindicativo; la tendencia al desánimo, al abandono (hasta apolítico electoral) y al «rebentisme» («o tot o rès», «totoressisme»: o el todo o nada), al fraccionalismo político y al empezar en cada nueva ocasión de cero frente a la constatación del hermetismo político centralizador y uniformizador de la política española.

Para analizar de forma sucinta la evolución y significación de este catalanismo durante la Segunda República abordaremos cuatro aspectos: las relaciones políticas del catalanismo con el Estado; la difícil convivencia entre catalanismo y obrerismo; los logros y límites de la nacionalización catalana (alternativa de la española) de la masa; y la difícil pervivencia de la politica catalanista durante la Guerra Civil.

\section{El catalanismo político frente al Estado español}

El efecto acelerador de la vida social, cultural y económica catalana que había tenido la Gran Guerra alcanzó, como no podía ser de otro modo, al catalanismo político: notable ampliación de su base social, desplazándose hacia sectores de la pequeña burguesía y de la clase trabajadora, en especial del sector servicios, ambos desestabilizados y radicalizados por la Guerra; nuevo estímulo nacionalista en el contexto determinado por los «Catorce Puntos» del presidente Wilson y la subsiguiente aparición de la Sociedad de Naciones; estructuración de la alternativa autonómica (1918-9) tras el fracaso del intento de reforma constitucional impulsado en buena parte por Cambó y la Lliga en la Asamblea de Parlamentarios (1917) que sitúa al catalanismo en el centro de la política española ${ }^{8}$; aparición del radicalismo nacionalista y de la primera opción separatista (la Federació Democràtica Nacionalista de Macià, de 1919); o la actualización de la oferta política catalanista, anteriormente monopolizada por la Lliga Regionalista, con la creación de la centrista Acció Catalana y el separatista Estat Català (1922) y de la Unió Socialista de Catalunya (1923), una opción socialdemócrata netamente catalana partidaria del establecimiento de un Estado federal que no fuese el resultado de una concesión desde arriba sino de un reconocimiento de la voluntad colectiva del pueblo catalán ${ }^{10}$.

7 Termes, Immigració i qüestió nacional, dentro de Les arrels populars del catalanisme, Barcelona, 1999, ps.113-129.

8 J.A. González Casanova, Federalisme i autonomia a Catalunya (1868-1938), Barcelona, 1975.

9 M. Baras, Acció Catalana (1922-1936), Barcelona, 1984.

10 Jesús Rodés, Socialdemocràcia catalana i questio nacional (1910-1934), "Recerques», 7, 1978 y J.Lluís Martín Ramos, La Unió Socialista de Catalunya (1923-1936), «Recerques», 4, 1973. 
Todo este dinamismo se producía y pervivía pese al desencadenamiento de la denominada «guerra social» (de una radicalidad e índice de violencia superiores a los de la Italia prefascista ${ }^{11}$ ) y a desembocar en el otro radicalismo antiparlamentario del golpe de Estado de Primo de Rivera y la posterior dictadura, de una especial virulencia anticatalanista. El dinamismo social, el inmovilismo oficial de la Restauración y las entreguerras, la aparición de grupos inicialmente muy minoritarios partidarios de la lucha armada. Mucho más numerosa fue la proliferación de ateneos, casas de cultura, grupos, círculos, peñas locales y de barrio, o de redacciones de publicaciones siempre efímeras, que tras el fracaso electoral de la Federació Democrática Nacionalista en las municipales de 1920 constituyeron un fundamental espacio apolitico de sociabilidad catalanista que iba a tener un protagonismo esencial en los años de la República. En ocasión de la celebración del 11 de setiembre de 1923 (en Barcelona se produjeron algunas muertes), el catalanismo lanzó la estrategia de la Triple Alianza, firmada en los locales del Centre Autonomista de Dependents del Comerç i la Industria con representantes vasquistas y galleguistas. Este pacto, con el nombre de GALEUSCA, sería ratificado en Guernica en 1934 (y posteriormente en México, en 1944) ${ }^{12}$.

La Dictadura llevó al exilio a muchos líderes catalanistas, el más destacado el «cabdill»» (caudillo) Francesc Macià, y dio alas al insurreccionalismo (en su ala más dura representado por Daniel Cardona; a destacar la organización «Bandera Negra», por los hechos de 1714, afín a Estat Català); incluso la moderada Acció Catalana creó el grupo secreto Serveis d'Estudis Militars para organizar la respuesta armada a la represión militar. En mayo de 1925 se frustró un atentado separatista en Garraf contra el tren que conducía al Rey, y en 1926 la policía francesa y los servicios secretos fascistas desbarataron el intento de invasión de Cataluña proyectado por Macià desde Prats de Molló. El posterior juicio en París dio gran popularidad a Macià, que tras su expulsión de Francia se lanzó a una intensa campaña propagandista, teórica (Constitución de La Habana, septiembre de 1928, redactada por Josep Conangla i Fontanilles y la creación del efímero Partit Separatista Revolucionari de Catalunya) y política con una notable repercusión en el interior de Cataluña.

Los fracasos del exilio reforzaron la vía interior, con una progresiva alianza entre Estat Català (que dirigía el médico socialista Jaume Aiguader), los grupos republicanos de Marcel-li Domingo y Lluis Companys, sectores de la agrarista Unió de Rabassaires, un grupo menestral y catalanista reunido en la asociación La Falç (con protagonismo del joven Josep Tarradellas ${ }^{13}$ ), los sectores elitistas republicanos y catalanistas reunidos alrededor del semanario L Opinió (1928) ${ }^{14}$ y contactos con sectores anarcosindicalistas: todos ellos tenían relación con la Alianza Republicana de Lerroux y un casi desconocido, Azaña, con la voluntad de crear un frente amplio antidictatorial. Otro aspecto relevante fue el movimiento de concordia intelectual promovido por Giménez Caballero y La Gaceta Literaria en 1927, concretando una notable movilización tanto en Cataluña como en España; esta iniciativa iba a trascender el espacio de la cultura por el mero hecho de representar un alegato antidictatorial frente a la dura represión padecida por la lengua y cultura catalanas; mucho más cuando en marzo de 1930 fue completada por los intelectuales catalanes al invitar a los colegas castellanos en agradecimiento de su solidaridad de 1927. Lo más significativo es que a principios de la «Dictablanda» la intelectualidad, con algunos de sus miembros

11 Albert Balcells, El sindicalisme a Barcelona (1916-1923), Barcelona, Nova Terra, 1965.

12 Xosé Estevez, De la triple Alianza al pacto de san Sebastián (1923-1930), San Sebastián, 1991 e idem, Galeuzca: la rebelión de la periferia (1923-1998), Madrid, 2009.

13 Jordi Casassas (coord.), 1899-1988. Tarradellas o la reivindicació de la memoria, Lleida, 2003.

14 Joan B. Culla, El catalanisme d'esquerra (1928-1936), Barcelona, 1977. 
comprometidos con la oposición política, explicitó por vez primera la idea de que la causa de Cataluña era indisociable a la consecución de la democracia en España ${ }^{15}$.

\section{El catalanismo y la aceleración política republicana}

Los meses de transición hacia la República fueron de una especial intensidad para el campo catalanista, quien junto a las campañas a favor de los presos sociales y políticos y las de demanda del restablecimiento democrático iba a centrar la vida política del período. La Lliga Regionalista fue la que más padeció los efectos erosionadores de la dictadura y, en especial, la falta de su líder, Francesc Cambó, que se recuperaba de una operación muy delicada en Londres ${ }^{16}$. Por su parte, los moderados de Acció Catalana superaron un intento de escisión de Antoni Rovira i Virgili (Acció Republicana y el periódico La Nau) y terminaran por crear el Partit Catalanista Republicà, al que la prensa predecía el máximo protagonismo político. Existía, además, la movilización de la izquierda catalanista, que intentaba promover con éxito escaso la convocatoria de una «Conferència d'Esquerres». La convocatoria de una reunión de la oposición española en San Sebastián (agosto de 1930) partió de la convicción de que la presencia del catalanismo era imprescindible, por lo que al Casino Republicano de la capital donostiarra acudieron Jaume Aiguader (Estat Català y Unió Socialista de Catalunya), Manuel Carrasco i Formiguera (Acció Catalana) y Macià Mallol (Acció Republicana). La resolución final preveía un alzamiento revolucionario (que a la postre fracasaría en todos sus frentes y llevaría a la cárcel a todos los miembros del Comité revolucionario) y, fuente de futuros conflictos sobre su interpretación, la adopción por las Cortes Constituyentes del texto de estatuto que Cataluña presentase una vez refrendado por el pueblo catalán ${ }^{17}$.

Tras el fracaso de la «revolución de diciembre», el catalanismo se centró en el posicionamiento frente a los sucesivos intentos de los gobiernos de Berenguer y Aznar de regresar a la normalidad constitucional y sus correspondientes convocatorias electorales. La Lliga fue la única fuerza partidaria del mantenimiento de la monarquía (en España promovió la candidatura del Centro Constitucional) y ello le acarrearía un importante retroceso electoral. El Partit Catalanista Republicà definió su alternativa en solitario. El resto de grupos promovió la convocatoria de una Conferència d'Esquerres a celebrar los días 18 y 19 de marzo de 1931 en el Foment Republicà de Sants. Pocas semanas antes había regresado del exilio Macià, rodeado de un indiscutible carisma de líder de multitudes y de gran prestigio en los medios catalanistas. En Sants se reunieron representantes del grupo de L 'Opinió que intentaran sin éxito (dado el claro rechazo de los centros comarcales) aportar un giro «socializante», la parte del nacionalismo radical de Estat Català afín a Macià, representantes de centros y ateneos locales, republicanos «tradicionales» con Companys de figura máxima, sectores disidentes de Estat Català y gente afín al doctor Josep Dencàs, que un par de dias antes había fundado el efímero Partit Social-Demòcrata Català. De esta conferencia resultará el nuevo partido, Esquerra Republicana de Catalunya, una veintena de días antes de la celebración de las elecciones municipales ${ }^{18}$. Ya desde el inicio, Estat

15 A. Balcells, Cataluña ante España. Los diálogos entre intelectuales catalanes y castellanos (18881984), Lleida, 2011.

16 I. Molas, Lliga Catalana. Un estudi d'estasiologia, Barcelona, 1972.

17 Manuel Carrasco i Formiguera, El pacte de Sant Sebastià, Barcelona, 1931 (su visión será criticada y desautorizada por Azaña y Maura).

18 M. Dolors Ivern, Esquerra Republicana de Catalunya (1931-1936), Barcelona, 1989. 
Català no disolvió su organización sino que la incrementó con los más radicales de Daniel Cardona y el grupo de Nosaltres Sols!, de reminiscencia irlandesa (diciembre de 1930), y con la movilización de las Juventudes, todo ello bajo el amparo del indiscutido Macià ${ }^{19}$.

Tras la inesperada victoria electoral del 12 de abril de 1931, el conglomerado de ERC aún crecerá más, se llenará de políticos de procedencias e intereses muy diversos, a menudo divergentes, y de arribistas con ansias de figurar; todo ello, más la dificultad de atender a tantos frentes de poder, convertirá a la Esquerra en una plataforma de equilibrio inestable tan sólo operativa por la gran capacidad de maniobra de Macià ${ }^{20}$. Una de estas disidencias se manifestó el 14 de abril con la doble proclamación en Barcelona, de una República sin definición (por lo tanto española) por Lluís Companys y la inmediata de Macià como República Catalana como «estat integrant de la Federació ibèrica» ${ }^{21}$. La proclamación secesionista del «Avi» (el abuelo, como se conocía popularmente a Macià) alarmó a algunos sectores catalanes (la Lliga apoyará la República, «però dins l'Estat español, amb una perfecta concòrdia amb tots els elements que el constitueixen ${ }^{22}$ ) y, especialmente, al Gobierno provisional de Madrid, alarma que se tradujo con la llegada a Barcelona (en avión, primera ocasión en la historia) de tres ministros negociadores: Marcel-li Domingo (Educación), Nicolau d'Olwer (Economía) y Fernando de los Ríos (Justícia). La verdad es que a Macià le costó relativamente poco ceder la independencia a cambio de presidir el gobierno provisional de la Generalitat de Catalunya (organismo de origen medieval sugerido por de los Ríos, especialista en derecho medieval). Ni que decir tiene que esta renuncia fue muy mal vista entre los sectores nacionalistas más radicales, que hablaron de traición, acentuó la heterogeneidad del partido (especialmente dentro de los cuadros dirigentes) y daría los primeros argumentos para la escisión de $1933^{23}$.

Con todo, ERC se había convertido en la fuerza política hegemónica en Cataluña (confirmada en las elecciones a Cortes Constituyentes del mes de junio) y durante un par de años pareció haber substituido definitivamente a la Lliga, desplazando el eje central del catalanismo de la burguesía hacia las clases medias y pequeño burguesas ${ }^{24}$. Con esta nueva hegemonía, el catalanismo se lanzó a la redacción del Estatuto y a la campaña de sensibilización para implicar al conjunto del país ${ }^{25}$. Claro está que debió plegarse a las exigencias españolas de subordinar la autonomía a la aprobación de la nueva Constitución, procedimiento unitarista que hacía olvidar cualquier veleidad confederal «pactada» en San Sebastián.

Sobre la base del proyecto de Estatuto de 1919, una comisión catalana se reunió en el monasterio de Nuria y redactó un texto que sería plebiscitado el 2 de agosto $(75 \%$ de participación y $99,45 \%$ de votos afirmativos; las mujeres, aún sin derecho a voto, reunieron unos centenares de miles de firmas en apoyo al texto $^{26}$ ). El momento era de notable efervescencia, con grandes fiestas patrióticas aguadas por las crecientes denuncias de la prensa madrileña por un hipotético pacto entre catalanistas y anarcosindicalistas, y de

19 Enric JARdí, Francesc Macià, Barcelona, 1991.

20 J.M. Poblet, Història de l'Esquerra Republicana de Catalunya (1931-1936), Barcelona, 1975.

21 Jaume Aiguader, Catalunya i la Revolució, Barcelona, 1931 i Ferran Soldevila Història de la proclamació de la República a Caralunya (ed. A cargo de Pere Gabriel), Barcelona, 1977.

22 Joan Estelrich, Catalanismo y reforma hispánica (prólogo de A. Ossorio y Gallardo), Barcelona, 1932.

23 Una visión general española en Justo G. BERAmendi / R. MAIz, edts., Los nacionalismos en la España de la $I^{a}$ República, Madrid, 1991.

24 La teorización, con final en el predominio nacional del proletariado en Joaquim Maurín, La revolución española: de la monarquía a la revolución social, Madrid, 1930 (1977).

25 Rovira i Virgil, Catalunya i la República, Barcelona, 1931 (reedición de 1977).

26 Arnau GonzÁlez, La imupció de la dona en el catalanisme, 1931-1936, Barcelona, 2006. 
consenso alrededor de la iniciativa catalanista, como se manifestaría en el triunfal viaje de Macià a Madrid para entregar el texto al Presidente de la República. A partir de este momento, sin embargo, el catalanismo entraría en la fase del desengaño. El Gobierno no crearía una comisión parlamentaria para discutir el texto catalán hasta enero del 1932 y aún ésta iniciaría los debates el mes de mayo y de forma intermitente (Azaña consideraba el tema autonómico equivalente al de la reforma agraria). Además, esta comisión laminaría el texto estatutario considerablemente, dejando a Cataluña como una «región autónoma» dentro del «Estado integral compatible con la autonomía de los municipios y las regiones». A pesar de las restricciones impuestas, en relación al uso del catalán, a la enseñanza en catalán, al mayor control estatal, a la disminución de las facultades autonómicas o a la falta de garantías de continuidad, el catalanismo no separatista confirió al nuevo texto un valor positivo ${ }^{27}$.

La Lliga Regionalista aceptó el nuevo contexto autonómico y, a fines de 1932, se reorganizó como Lliga Catalana, asumiendo un tono más liberal y una estructura moderna, para convertirse en portavoz de los sectores industriales y de la propiedad agraria y en la principal fuerza de oposición a la ERC ${ }^{28}$. En el sector moderado, el catalanismo católico y liberal, molesto con el laicismo de la Constitución, fundó Unió Democrática de Catalunya ${ }^{29}$.

En España, la discusión del Estatuto desencadenó reacciones de todo tipo: campañas en contra, boicot a productos catalanes (Castilla y Andalucía), manifestaciones universitarias (Sevilla, en contra de la enseñanza en catalán), etc. En el plano intelectual y político, los ataques fueron constantes, demostrando que la concordia de 1930 había desaparecido a partir del momento en que el catalanismo había llevado a la práctica su planteamiento reivindicativo ${ }^{30}$. Rovira i Virgili observó que las viejas declaraciones favorables se habían desvanecido dejando paso al «alma unitaria», a los «sentimientos de nacionalismo español, de nacionalismo castellano», a las propuestas minimizadoras en el sentido de que pudieran ser todas las regiones las que pudiesen ejercer las mismas facultades (Ortega y Gasset $)^{31}$. El mismo Rovira i Virgili, destacado historiador, periodista y representante del republicanismo catalanista, recuperó una frase de Almirall de 1886, muy indicativa del estado de ánimo que se afianzaba en Cataluña: «Vosaltres, castellans castellanistes, sou més entusiastes que el més intransigent dels defensors del catalanisme» (es decir que sarcásticamente los presentaba como agentes pro catalanistas involuntarios), añadiendo que el hecho de la Cataluña nación no precisaba de ninguna definición ni constitucional, ni estatutaria o legal: lo que se necesitaba era el reconocimiento democrático de la voluntad de un pueblo con personalidad propia ${ }^{32}$.

En medio de un creciente desánimo, ante la constatación de que sólo prevalecía la fuerza del Estado y de que tan sólo el intento de golpe de Estado protagonizado por el general Sanjurjo en Sevilla (10 agosto de 1932) iba a precipitar la aprobación del Estatuto ( 9 de septiembre), la vida política catalana entraría en la fase autónoma con pocos traspasos y menor financiación ${ }^{33}$.

27 A. Rovira i Virgll, La Constitució interior de Catalunya, Barcelona, 1932 (facsímil de 2005).

28 I. Molas, op. cit.

29 Hilari Raguer, La Unió Democrática de Catalunya i el seu temps (1931-1939), Barcelona, 1976.

30 Vid., por ejemplo, A. Royo Villanova, Treinata años de politica antiespañola, Valladolid, 1940.

31 Rovira I Virgil, La igualtat de les regions, La Publicitat, Barcelona (18/09/1931).

32 Rovira i Virgil, De Núnez de Arce a Unamuno, La Publicitat, (1/10/1931).

33 Uno de los principales negociadores del catalanismo, junto con Jaume Carner, frente al gobierno central será Amadeu Hurtado, del que recomendamos la utilización de la nueva edición de sus memorias, Quaranta anys d'advocat. Història del meu temps (1894-1936), Barcelona, reedición de 2011. 
Dentro del catalanismo reaparecieron las tensiones: críticas, hasta internas, sobre la baja calidad y la improvisación de los dirigentes de la ERC, descalificaciones y burlas personales, creciente acidez de la prensa política y satírica, proliferación de manifestaciones de las Juventudes separatistas y sus «escamots» con formas cada vez más «fascistas». Estas tensiones provocaron la crisis del gobierno de diciembre de 1932 en el que colaboraban republicanos y socialdemócratas (Tarradellas, Xirau, Lluhí Vallescà, Pi i Sunyer, ete.), en polémica creciente con la gente de Estat Català. La solución de Macià fue la convocatoria de un congreso extraordinario ( 7 de octubre de 1933) en que se consumó la expulsión del grupo de L'Opinió (conocidos como los «lluhins») los cuales no tardaran en fudar su partido, el Partit Nacionalista Republicà d'Esquerra (PNRE, conocido despectivamente como «Panarra», los que se hartan de pan ${ }^{34}$.

Estas divisiones del catalanismo de izquierdas van a comportar, en las elecciones generales de noviembre de 1933, un gran retroceso de sus candidaturas, junto al avance de la Lliga Catalana que se convertirá en la primera fuerza política del país ${ }^{35}$. Además, una gripe mal curada precipitará la muerte de Francesc Macià, el día de Navidad de aquel año. En medio de esta crisis fue elegido nuevo presidente de la Generalitat Lluís Companys (el 31 de diciembre), quien formó gobierno el 3 de enero siguiente con la pretensión de minimizar la fuerza de influencia del separatismo y de establecer los contactos, ahora defensivos, con las izquierdas españolas en la oposición frente al triunfo de la CEDA en España (la lucha contra las fuerzas «monarquizantes y fascistas», dirá). Propuso una alianza con la USC e incluso con grupos marxistas de reciente creación y radicalizó progresivamente los planteamientos para responder a las expectativas de la izquierda española, que empezó a considerar Cataluña como el «baluarte de la República».

Como es sabido, el pleito abierto entre, por un lado, ERC y, por el otro, la Lliga y la asociación de propietarios (Institut Agrícola Català de Sant Isidre), en colaboración con el Partido Agrario Español, que en concurrencia con otras fuerzas de derechas crearan Acció Popular Catalana, a raíz de la aprobación en el Parlamento catalán de la Llei de Contractes de Conreu (de arrendamientos) y la posterior intervención del Tribunal de Garantías crispó el clima político, con el resultado de la proclamación confederal de Companys el 6 de octubre de $1934^{36}$. La proclamación de Companys, en la línea de la de Macià el 14 de abril, parece que le llevó a susurrar «ja no diran que no soc catalanista» en frase significativa de las tensiones internas del mundo catalanista ${ }^{37}$. A pesar de la prudencia del general Batet en controlar la situación (esta moderación y la negativa a sumarse al Alzamiento le valieron ser fusilado por Franco en 1937), el gobierno catalán y otras autoridades fueron encarceladas, Catalunya fue sometida a un gobierno militar hasta que en enero de 1935 se nombró Gobernador General de Cataluña a Manuel Portela Valladares, los registros policiales y las clausuras de sociedades catalanistas se multiplicaron y la autonomía quedó prácticamente anulada (la lengua oficial de la Generalitat pasó a ser el castellano, se prohibió izar la bandera catalana, etc. ${ }^{38}$. En esta coyuntura tan negativa («Bienio Negro»), la Lliga Catalana se convirtió en un elemento de relativa moderación del ensañamiento anti

34 Oriol Malló, Tarradellas. Un segle de catalanisme, Barcelona, 2003.

35 Mercedes Vilanova, Atles electoral de Catalunya durant la Segona República, Barcelona,1986.

36 Ismael Pitarch, L'estructura del Parlament de Catalunya i les seves funcions politiques (1932-1939), Barcelona, 1977.

37 Teresa Abelló / J. M. Solé SABAté (coord), Lluis Companys, president de Catalunya: biografia humana i politica, 2 vols., Barcelona, 2007.

38 Claudi Ametlla, Memòries politiques, vol. II, Barcelona, 1979. 
autonómico general; pero ello no fue óbice para que se acrecentase su descalificación como fuerza anticatalana. Tras los hechos de octubre, la Lliga creará el semanario Después de un tono antiseparatista muy acusado (con gente como J. M. Tallada, Ferran Valls i Taberner, M. Vidal i Guardiola, Andreu Bausili, etc.).

\section{La difícil convivencia entre catalanismo y obrerismo}

Junto al catalanismo, el obrerismo es la otra gran fuerza dominante de la Cataluña del primer tercio del siglo XX y, como en el caso del primero su trayectoria durante la Segunda República, debe entenderse desde la dinámica retrospectiva que parte de la coyuntura de impacto de la Gran Guerra y desemboca en los años nefastos de la «guerra social» (1919-1921) y de la represión y desmovilización producidas por la dictadura ${ }^{39}$. En esta secuencia de tanta tensión, las críticas contra el «nacionalismo burgués» alimentadas por el lerrouxismo desde principios de siglo fueron constantes y determinaron en gran medida las enormes dificultades que encontró el obrerismo para compaginar la liberación social con la nacional. Existieron puntos de contacto, durante los años de Solidaritat Catalana y durante la Gran Guerra y la radicalización del catalanismo progresista y de izquierdas: a través de los contactos entre el anarcosindicalista Salvador Seguí ( «E1 Noi del Sucre» $)^{40}$ y Francesc Layret, ambos asesinados por el pistolerismo «blanco» en 1923 y 1920 respectivamente; o los contactos en el mundo socialista, tradicionalmente contrario al nacionalismo (y por extensión al catalanismo $\mathrm{o}^{41}$ ), con las disputas más académicas dentro de la Federación Catalana del PSOE desde 1914 (polémica sobre la doble vía, social y nacional), acrecentadas con la recepción del «wilsonismo» (1918) y que desembocarían en la polémica de 1923 entre Antoni Fabra Ribas y Rafael Campalans (secundado por Manuel Serra i Moret), antesala de la escisión catalanista que daría origen a la Unió Socialista de Catalunya aquel mismo año ${ }^{42}$.

Los años de clandestinidad durante la dictadura incentivaron los contactos, divisiones y fusiones de manera muy especial en el campo obrerista, así como la primera aparición de un comunismo catalán ${ }^{43}$. La minoritaria USC reclamaría sin éxito en 1924 la creación de un amplio frente anti dictatorial. Luego, a la caída de la dictadura inició su reestructuración interna (bajo la presidencia de Gabriel Alomar) manteniéndose fiel a su concepción federal inicial pero con unos tintes particularistas que ponían el énfasis en el reconocimiento de la voluntad mayoritaria de los catalanes (adopción del principio de autodeterminación), y sumándose sin participar a la visión catalana de lo pactado en San Sebastián como primer paso de su confluencia con la corriente que acabaría creando ERC. Frente a la proclamación de Macià, el 14 de abril, Campalans lanzaría el manifiesto «Al Poble de Barcelona» donde la consideraba la declaración «de la plena independencia» de Cataluña con voluntad

39 Balcells, Ideari de Rafael Campalans, Barcelona, 1973; y J. Rodés, Moviment obrer i catalanisme durant la Segona República. Una aproximació estasiològica: la USC, UAB. tesi doct.).

40 Seguí consideraba que quien pondría más trabas a una hipotética independencia de Cataluña sería la derecha de la Lliga; I. Molas comp.,Salvador Seguí. Escrits, Barcelona, 1975.

41 Una teorización de estas tensiones con su marco internacional en Andreu NiN, Els moviments d'emancipació nacional. L'aspecte teòric i la solución pràctica de la qüestió, París, 1970 y La cuestión nacional en el estado español, Barcelona,1979: con duras críticas a la filiación nacional de la socialdemocracia y su contribución al paroxismo ultranacionalista a partir de 1914.

42 J. RodÉs (comp.), Catalanisme i socialismo. El debat de 1923, Biblioteca dels Clàssics del Nacionalisme Català, 10, Barcelona, 1985.

43 Balcells, Marxismo y catalanismo (1930-1936), Barcelona, 1977. 
de confederarse con el resto de pueblos ibéricos, un hecho revolucionario que según él representaba la «liberación nacional y su consolidación como nuevo Estado nacional» ${ }^{44}$.

La colaboración catalanista de la USC con ERC llevaría a su líder Campalans a integrar la ponencia redactora del Estatut, a participar activamente en la campaña del Referéndum y en las protestas posteriores frente al trato de las Constituyentes para con el texto catalán, llegando al punto de verse obligados a declarar que no les movía un ánimo chauvinista, sino que actuaban tácticamente para acelerar la resolución satisfactoria del pleito político catalán, que dejaría las manos libres a la juventud para avanzar en la vía de la revolución social ${ }^{45}$. Estuvieron presentes en muchos de los gobiernos de la Generalitat, colaboraron activamente con Companys con la idea que Cataluña era el último «refugio de la revolución», y ante el peligro de derechización general declararían luchar por la independencia de Cataluña «total i absoluta». «Però no som catalanistas», precisarían. En 1933 se frustró el intento de fusión entre la USC y la Federación Socialista Catalana que se consumaría en julio de 1936 con la creación del PSUC ${ }^{46}$.

En el mundo anarcosindicalista, la dictadura estimuló la creación de la FAI (Valencia, 1927 aunque inoperante hasta 1930-1), organización mucho más radical que fue vista como un cuerpo extraño a la tradición anarquista catalana por parte de un grupo (Joan Peiró y otros) que crearía una tendencia conocida como los «Trentistes» (1930), en principio favorable a la proclamación del 14 de abril y al proceso estatutario ${ }^{47}$. Frente a la posterior obra legislativa de la Generalitat, amplios sectores de la CNT se mostraron favorables a ella, especialmente en el campo de la legislación social, aunque fuese de forma más táctica que otra cosa, puesto que pensaban que la cercanía y su creciente peso social en Cataluña les darían mayor posibilidad de influencia y control. Aún en la más radical FAI existieron elementos favorables al «particularismo catalán»: así, Federico Urales (Joan Montseny), quien además teorizó sobre el determinismo geográfico y económico acerca del carácter catalán distinto del español.

Se ha hablado de una cierta «luna de miel» del obrerismo catalán con el gobierno de la Generalitat y la historiografía ha debatido hasta qué punto la crisis económica mundial afectó a la estabilidad de la República española ${ }^{48}$, sea como fuere, lo cierto es que existe una cierta relación entre el paro forzoso y la agitación social ${ }^{49}$; y que el «faïsmo» mayoritario provocó el levantamiento del Alto Llobregat (enero de 1933) y desencadenó la agitación insurreccional en el enero siguiente. Sin embargo, el tema nacional estuvo siempre presente en la movilización de los grupos obreristas del período, muy activos dado el grado creciente de insatisfacción que se producía en un medio que seguía pensando que la liberación social debía producirse en meses y culpaba a la democracia burguesa de su retraso, a la irrupción del marxismo y a la tendencia natural a producir escisiones y refundaciones.

Los grupos en un grado u otro marxistas fueron numerosos: en 1924, se había creado la Federació Comunista Catalano-Balear (que en 1933 pasará a denominarse Federación

44 Manuel GERPE, El estado integral y el Estatuto de Autonomia de Cataluña, Barcelona, 1974.

45 Rafael Campalans, Hacia la España de todos. Palabras castellanas de un diputado por Cataluña (prólogo de Gabriel Alomar), Barcelona, 1932.

46 J. Lluís Martín Ramos, Els origens del Partit Socialista Unificat de Catalunya (1930-1936), Barcelona, 1977.

47 Eulalia VEGA, El trentisme a Catalunya. Divergències ideologiques en la CNT (1930-1933), Barcelona, 1980.

48 Artal/Guasch/Massana/Roca, El pensament economic català durant la República i la Guerra (19311939), Barcelona, 1977.

49 Balcells, Crisis económica y agitación social (1930-1936), Barcelona, 1971. 
Comunista Ibérica); en 1928, Jordi Arquer y otros pocos crearan el Partit Comunista Català; en 1930, y fruto de la unión de gente procedente del Partit Comunista Català (independent), de la Federación Catalano-Balear y disidentes de la III ${ }^{\mathrm{a}}$ Internacional, fundaron el Bloc Obrer i Camperol (Arquer y Jaume Miravitlles) s. $^{50}$ en 1932, Jaume Comte impulsará la escisión Estat Català-Front Separatista d'Extrema Esquerra (enero de 1932), poco después denominada Estat Català Proletari ${ }^{51}$. Todos ellos incorporaron las tesis leninistas relativas al reconocimiento del derecho a la autodeterminación y fueron favorables al referéndum del Estatuto $^{52}$. A su lado existirá el Partit Català Proletari (partidario de incorporar Cataluña en una Unión Mundial de Repúblicas Socialistas) y el Partit Obrer d'Unificació Marxista (POUM) de 1935, de corte leninista pero que no integraba el tema nacional en sus prioridades sino que se preparaba para cuando los acontecimientos acabasen con la política pequeño burguesa de ERC. Finalmente, en julio de 1936, el PSUC no escondió su voluntad de remplazar la hegemonía de ERC y captar a la masa nacionalista con sus propuestas socialdemócratas.

\section{La nacionalización catalana de las masas}

Llegados a la altura de la Gran Guerra (a la que el catalanista progresista, historiador y agudo periodista Rovira i Virgili denominó «la guerra de las naciones») ${ }^{53}$, todo nacionalismo de una sociedad mínimamente industrializada, como era el caso de la catalana, tenía perfectamente claro que uno de sus objetivos principales consistía en la nacionalización de su ciudadanía. El nacionalismo catalán se hallaba en esta tesitura pese a no disponer de la estructura de un Estado propio (por lo tanto se trataba de una nacionalización alternativa a la general española), y a ello dedicó todos los esfuerzos de aquel organismo supra provincial y de competencias exclusivamente administrativas que se puso en marcha en 1914 con el nombre de Mancomunitat de Catalunya y que pervivió hasta su definitiva disolución por Primo de Rivera en 1925.

Recogiendo iniciativas de diversa procedencia (organismos profesionales, escolares, de excursionismo cultural, técnicos, científicos, etc.), sistematizando y ampliando lo avanzado por los equipos de Prat de la Riba en la Diputación de Barcelona y agrupando a los mejores especialistas sin reparar en su filiación política (se hablará de intelectualidad burocrática), la Mancomunitat llevó a cabo una tarea ingente (denominada de «Catalunya endins», hacia dentro) que no guardaba relación con sus capacidades legales ni con sus posibilidades y recursos. Destacaron la atención hacia las infraestructuras y la integración territorial ${ }^{54}$, la obra cultural (de la alta cultura a la popular), la promoción de la mujer y la obra educativa en todos sus grados (sobresaliendo la puesta en marcha de una Universidad Industrial para la capacitación y promoción de la masa obrera) ${ }^{55}$. Especialmente tras la Guerra del 14 buena parte de los dirigentes de este organismo, a pesar de provenir algunos de los sectores conservadores de la Lliga Regionalista, tuvieron muy clara la necesidad de atender como

50 Francesc Bonamusa, El Bloc Obrer i Camperol (1930-1932), Barcelona, 1974.

51 Imma Tubella, Jaume Comte i el Partit Català Proletari, Barcelona, 1979.

52 Rioger ARNAU (Josep Benet), Marxisme català i qüestió nacional catala (1930-1936), Barcelona, 1974.

53 Morley, captain (seudónimo de Rovira i Virgili), La guerra de les nacions: història documentada, 5 vols., Barcelona, 1914-1925 (especialmente vol. 5).

54 Francese Roca, Politica económica i territorio a Catalunya (1901-1939), Barcelona, 1979.

55 Resulta de especial interés Enric UCELAY DA CAL, La Catalunya populista: imatge, cultura i politica en l'etapa republicana (1931-1939), Barcelona, 1982. 
una prioridad a la «cuestión social»; hablaban asiduamente de «concordia de clases», de intervención pública en las relaciones entre capital y trabajo, de «socialismo liberal» (crearon en 1922 un Institut Català de Previsió, Treball i Estalvi», ahorro) e intentaron contrarrestar el anticatalanismo de los sindicatos y de la Federación Patronal. La actuación más significativa en el orden nacionalizador fue la puesta en marcha de una Comisión de Educación General (1920-2) como organismo técnico encargado de estructurar el Institut d'Educació Nacional ideado por Prat de la Riba para atender a la formación física, moral y social del pueblo. Antes de la dictadura se organizaron o proyectaron, entre otros, el servicio de «ensenyament domèstic i agrícola ambulant», ciclos de conferencias, campañas como la del «menjar i del bon gust català», de embellecimiento de los hostales de Cataluña, un «servicio de subvenciones» para acciones de mejora y promoción de actividades lúdicas, una campaña de protección de la imaginería popular, de educación física, de higiene individual y «social», de «profilaxis general», de educación musical, de estética urbana, de moral sexual, de educación moral, de catalanización de la enseñanza, de atención a las «dolencias sociales» (alcoholismo, prostitución, juego, narcóticos, violencia, etc.), con distribución masiva de folletos, fijación de carteles, etc. ${ }^{56}$.

La dictadura desbarató todos estos planes pero se mantuvieron los equipos, la sensibilidad para con la tarea nacionalizadora y el funcionamiento de instituciones de la sociedad civil orientadas explícitamente a estos fines ${ }^{57}$. Entre estas instituciones podemos destacar la Associació Protectora de l'Ensenyança Catalana, Nostra Parla y Palestra Organització Nacional de la Joventut Catalana. Nostra Parla había sido creada en 1916 para impulsar la unidad lingüística de todos los territorios de habla catalana y desaparecería en 1923, a causa de la política represiva en materia lingüística de la dictadura. De mayor trascendencia fue la APEC, creada en 1898 por impulso de la Unió Catalanista, reflotada por la Mancomunitat bajo la presidencia de Manuel Folguera i Duran: organizó cursos, campañas de difusión de la cultura catalana y animó una Editorial Pedagògica (presidida por Pompeu Fabra) que entre 1917 y 1936 publicó una cuarentena de libros; durante la República tendría unos 8000 socios.

El organismo más significativo del periodo republicano fue Palestra, creado en 1930 por el patriota J. M. Batista i Roca y del que fue presidente hasta la Guerra Pompeu Fabra (con una leve interrupción a raíz de los hechos de octubre de 1934) ${ }^{58}$. El objetivo de Palestra era la formación de la juventud entendida como los futuros ciudadanos y realizarlo expresamente al margen de los partidos políticos, equidistante de la derecha y la izquierda, $\sin$ ayudas oficiales y neutral en materia religiosa. Su fundador se había inspirado en el movimiento Checo «Sókol» y como éste combinaba la formación deportiva con la intelectual y la difusión de los valores sobre los que se asentaba la identidad catalana en lo que denominan la «tarea ingente de recatalanización de la sociedad» (crearan un Servei de Difusió Cultural), luchando por contrarrestar el anticatalanismo y poniendo fin a la etapa de las teorizaciones para pasar a la acción con un acercamiento real al pueblo. Primaron la educación patriótica de la infancia y afirmaran la intención de recuperar los ideales del «imperativo ético» y del «tradicionalismo evolutivo» que habían inspirado a Prat de la Riba en su proyecto de despertar en la masa «la conciencia de patria». De hecho puede decirse que, en buena medida, el proyecto de Palestra proviene de la Comisión de Educación General ya comentada. No obstante, los jóvenes de 1930 tienen plena consciencia de participar de una

56 Jordi CASASSAS, Jaume Bofill i Mates: l'adscripció social i l'evolució politica, Barcelona, 1980.

57 Citemos el caso de C. Pi i Sunyer y su intento de democratización cultural siguiendo las pautas del noucentista, en L 'aptitud econòmica de Catalunya, 2 vols. (1927 y 1929), reedición, Barcelona, 1983.

58 Lluís Duran, Intel-ligència i carácter. Palestra i la formació dels joves (1928-1939), Catarroja, 2007. 
nueva generación, con menos límites que la de principios de siglo, plenamente consciente de que la tarea nacionalizadota era indisociable de la de la democratización del país ${ }^{59}$.

La marcha de la República convenció a algunos comentaristas de que el republicanismo catalán, diversamente de lo que sucedía en el resto de España, había conseguido introducir cambios reales en la sociedad catalana, e impulsado una «revolución política» que habría generado un «nuevo estado social» con el resultado de atraer finalmente las masas hacia el catalanismo; aunque eran plenamente conscientes de que la masificación conllevaba una mengua de la conciencia nacional y de la calidad de los cuadros intermedios. Pero, como apuntó el periodista y novelista Doménech Guansé (y en ello coincidían gente como Gabriel Alomar, Pere Coromines, Rovira i Virgili, etc.), la izquierda nacional habría realizado por vez primera la conexión entre la esencia del pueblo (la catalanidad) y la cultura entendida como el vehículo de expresión de esta esencia (el catalanismo); la política del nacionalismo de izquierdas debía centrarse, pues, en proporcionar a las masas la cultura de que no disponían (escuelas, instituciones de enseñanza, bibliotecas, etc.) y estimular una creación cultural inasequible hasta entonces para el pueblo, sin caer en «el perill de les democràcies», que era el de el de «diluir la cultura ${ }^{60}$.

Palestra dedicó una atención especial a la historia y a las conmemoraciones, a la geografía y a la economía. En 1933 promocionó la celebración del centenario de la Renaixença y repartió 20.000 ejemplares de un folleto explicativo con estadísticas, un compendio de artículos y unos trabajos dedicados a glosar la situación política de su presente y a presentar un resumen de la evolución del catalanismo.

Que se había avanzado en la nacionalización catalana de la masa parece bastante claro: la escuela catalana hacía esu función y un activo sistema de colonias escolares, la proliferación de ciclos y cursos nocturnos y dominicales, etc. sirvieron para ampliar el abanico social de los nacionalizados; todo contando con el estímulo que significó la euforia política que envolvió el cambio de régimen y su mantenimiento con la campaña pro Estatuto y (ahora ya más en negativo) todo el proceso de su tramitación parlamentaria y los agravios que se iban acumulando. Entre las élites políticas, esta catalanización parece indiscutible y se dejaba entrever por debajo la lógica confrontación de proyectos políticos distintos ${ }^{61}$. Los cambios en la toponimia urbana y su tramitación, su correspondiente en la monumentalística ${ }^{62}$, el tono de los discursos conmemorativos, la actualización de los libros de texto, las constantes referencias histórico-patrióticas de los discursos políticos o la proliferación de trabajos de reflexión retrospectiva en la prensa y en las cada vez más numerosas revistas de calidad (Mirador, La Rambla, D'Aci D 'Allà, etc.) confirman el alcance de esta nacionalización. Por otra parte, puede constatarse una cierta coincidencia en una única y coincidente memoria histórica nacional entre los políticos de derechas (Lliga Catalana) y de izquierdas (ERC): la referencia a 1640 y 1714 (y la interpretación del 14 de abril como la definitiva victoria sobre los Borbones), a la gloriosa Edad Media y su expansionismo mediterráneo o a diversos aspectos de la Renaixença de 1833, se van convirtiendo en recurrentes en todos los campos. En todo caso, la confrontación se centró en las distintas lecturas que se daban a una identidad nacional que no se euestionaba: así, la interpretación conservadora, sensibilizada por el debate constituyente, cargaba las tintas en la filiación tradicional y religiosa de la

59 Félix Cucurull, Catalunya, republicana i autónoma (1931-1936), Barcelona, 1984.

60 Doménech Guansé, Politica $i$ cultura.L'entrada de la massa en el catalanisme, «La Rambla», 228 (30/04/1934), citado por E.U. DA CaL, op. cit., p. 17-8.

61 Pere Bosch Gimpera, Memòries, Barcelona, 1980.

62 Oriol Bohigas, Arquitectura i urbanisme durant la Segona República, Barcelona, 1970. 
identidad, mientras que la de izquierdas ponía el acento en la vertiente progresista y laica, soportando estas visiones las respectivas lecturas que se hacían de las personas-símbolo, de las instituciones representativas y de las coyunturas históricas aleccionadoras ${ }^{63}$.

\section{Grandes dificultades durante la Guerra civil}

Desde fines de 1935 dirigentes de ERC que se habían librado de la cárcel (como Carles Pi i Sunyer ${ }^{64}$ ) establecieron contactos en Cataluña y Madrid para reconstruir un Frente de Izquierdas, al estilo del Ressamblement Populaire que se acababa de poner en marcha en Francia para luchar contra el peligro fascista; incluso adoptaron su emblema de las tres flechas apuntando hacia abajo y cubriendo las siglas SFIO, aquí convertidas en cuatro flechas rojas hacia arriba que recuerdan las cuatro barras de la bandera catalana. De esta movilización surgiría el Frente Popular y su triunfo en las elecciones del 16 de febrero de 1936. En Cataluña, la victoria de las izquierdas y el viaje triunfal de Companys y los otros dirigentes de regreso a Barcelona dio la sensación de que ERC se recuperaba de la gran crisis abierta en 1933 y agudizó la confrontación entre derechas e izquierdas ${ }^{65}$. Durante la campaña e inmediatamente después de la victoria se reincorporaron a ERC grupos como Renovació Catalanista Republicana o el grupo de L'Opinió y su PNRE y contribuyeron a subordinar en parte la hegemonía de Estat Català y las corrientes separatistas ${ }^{66}$. Por unos meses, y pese a la tensión creciente, pareció que ERC recuperaba aquella vitalidad social que había singularizado la vida catalana durante los dos primeros años de la República ${ }^{67}$.

Como es lógico, el inicio de la guerra y el desencadenamiento de la revolución social crearon una situación excepcional que hicieron muy difícil la vida para las posturas republicanas y demócratas (ni que decir tiene para las conservadoras), espacios donde se asentaba con mayor fuerza el catalanismo ${ }^{68}$. La intelectualidad que había dado sentido y profundidad al catalanismo se vería enseguida desbordada por la guerra y en una situación a menudo muy comprometida a pesar de que entre ellos eran sólo una ínfima minoría los simpatizantes con el bando sublevado. Los afines a la Lliga Catalana o de significación católica debieron exiliarse o tratar de pasar desapercibidos, situación que también alcanzó a intelectuales de la órbita de ERC, como Ventura Gassol. Otros, de izquierdas, combatieron incluso con las armas (Pere Calders, Joan Sales, Avel-lí Artís-Gener y otros) o se afiliaron a sindicatos y partidos marxistas (especialmente en el recién creado PSUC) para trabajar con cierta protección.

La máxima labor de esta intelectualidad se desarrolló alrededor de la Conselleria de Cultura de la Generalitat y sus programas de popularización cultural en catalán bajo la batuta de Antoni M. Sbert o Carles Pi i Sunyer. La Conselleria creó premios literarios, de periodismo, ensayo o teatro e incluso confiscó instituciones (Ateneo Barcelonés) y obras culturales (como la Colección Bernat Metge) para salvarlas de la furia revolucionaria. Se creó el Serveis de Cultura al Front i el Servei de Biblioteques al Front (algunas con

63 Fernando SÁnchez Costa, Memória pública $i$ debat politic a Barcelona (1931-1936). L'ERC $i$ la Lliga Catalana davant el passat i el futur de Catalunya. Tesis doctoral, Universitat internacional de Catalunya, 2011, http:/hdl.net/10803/50993.

64 Carles Pi i Sunyer, La República y la Guerra. Memorias de un politico catalán, México, 1975.

65 Pere Coromines, La República i la Guerra Civil, diaris i records, Vol. III, Barcelona, 1975.

66 M. CRUELLs, El separatisme català durant la Guerra Civil, Barcelona, 1978.

67 Ramon Alquezar coord.Esquerra Republicana de Catalunya.70 anys d'historia (1931-2001), Barcelona, 2001.

68 Francesc Cамвó Memòries (1876-1936), Barcelona, 1981. 
unidades móviles) donde se publicaron obras de divulgación de la realidad y la cultura catalanas de una notable calidad, de parte de gente como el historiador Ferran Soldevila o el geógrafo Pau Vila, así como antologías de poesía de gran calidad.

Destacó la creación del Comissariat de Propaganda (octubre de 1936) del que se encargó el periodista Jaume Miravitlles y que desarrolló una actividad intensa con publicaciones, exposiciones, campañas propagandísticas con carteles de una calidad notable (por ejemplo, el cartel de Ricard Fábregas con la leyenda «Sempre! Catalans $=$ Catalunya!» $)^{69}$, cuadernos fotográficos (destacará la labor de Agustí Centelles), con revistas y boletines, cine (la productora Laia Films ${ }^{70}$ ) o la campaña de distribución masiva de la estatuilla «El més petit de tots» representando a un chico con el puño en alto sosteniendo la bandera catalana y que se convirtió en uno de los emblemas de la Cataluña en guerra. También debemos destacar la creación por la Generalitat del Consell de l'Escola Nova Unificada (CENU) que actuó desde fines de julio del mismo 1936. Con él se imponía un modelo de escuela pública y gratuita en catalán, no confesional y en régimen de coeducación. Actuó con relativa normalidad hasta 1937, no así en 1938, cuando entre otras cosas había una carestía real de papel, los bombardeos sobre núcleos urbanos eran frecuentes y la llegada masiva de inmigrantes de las zonas que iba ocupando el ejército sedicioso contribuyó a desintegrar la obra del CENU.

En el plano político, el catalanismo debió centrar sus esfuerzos en mantener la existencia y la operatividad de la Generalitat, inicialmente frente al predominio cenetista y revolucionario, pero especialmente tras los hechos de mayo de 1937 frente a los embates anti autonómicos del estado central. Durante los primeros meses de la guerra, las dificultades bélicas limitaron la capacidad de control del Estado central y ello permitió que la Generalitat (en buena parta gracias a la gran decisión de personas como Josep Tarradellas) ejerciera competencias no previstas en el Estatuto ${ }^{71}$. El mismo Azaña escribió que la Generalitat actuó «insurreccionada» contra el Gobierno de la República, llegando a legislar y usurpar competencias centrales (servicio de aduanas, Banco de España, policía de fronteras, Industrias de Guerra, etc.) utilizando de forma «miserable» la coartada de actuar para impedir los abusos de la $\mathrm{FAI}^{72}$.

Se fue extendiendo la idea del egoísmo catalán, de que Cataluña se preocupaba tan solo de sus asuntos y de defender su territorio, despreocupada por la suerte que pudiese correr la República ${ }^{73}$. Indalecio Prieto y Juan Negrin opinaban abiertamente que Catalunya no habia participado en la guerra sino que la había aprovechado en provecho propio. Ahora, en función de la defensa suprema de la República, se lanzaron fuertes campañas de exaltación patriótica española y en contra de Cataluña: unas campañas que «olvidaban» la movilización emprendida por la Generalitat de Catalunya en defensa de Madrid («Defensem Madrid»). Este discurso se recrudecería tras los hechos de mayo de 1937 y, aún más, a partir del traslado del gobierno central de Valencia a Barcelona, el mes de octubre. Tras la derrota, los mismos conflictos lastraron la política del catalanismo (disputas entre ERC y el PSUC) e incluso la gestión del exilio en dura pugna entre la Generalitat y el Gobierno central.

69 J. Termes/Jaume Miravitlles/Carles Fontsere, Carteles de la República y la Guerra Civil, Barcelona, 1978.

70 J.M. CAPARrós, El cine republicano español (1931-1939), Baarcelona, 1977.

71 AA.VV., L'obra de govern de Josep Tarradellas (1936-1977), Lleida, 2008.

72 AzANa, La velada de Benicarló, Madrid, 1974.

73 El fundamento cultural de este desencuentro de largo recorrido en Horts HinA, Castilla y Cataluña en el debate cultural, Barcelona, 1986. 
Después de la caída de Teruel y de la derrota republicana en el Ebro, el ejército de Franco inició la conquista de Cataluña. El 5 de abril de 1938, ya en territorio catalán, Franco firmaría el decreto de derogación del Estatuto de Cataluña «en mala hora concedido por la República», para restablecer «un régimen de derecho público que, de acuerdo con el principio de unidad de la Patria, devuelva a aquellas provincias el honor de ser gobernadas en pie de igualdad con sus hermanas del resto de España».

Uno de los políticos, periodistas, historiadores y teóricos del catalanismo, el ya citado Antoni Rovira i Virgili, tras la derrota y en el exilio afirmaba que para los catalanes había llegado un «temps de meditació». Recordaba que habían sido dos militares, dos dictadores, quienes habían terminado por la fuerza con la Mancomunitat y la Autonomía, y realizaba un breve repaso histórico de la persistencia del espíritu anti catalán para concluir que «la solución del problema català dintre d'Espanya, és si no imposible, almenys extremadament difícil». Su conclusión estaba de acorde con el pesimismo de aquellos momentos: los catalanes -decía- debemos tener plena conciencia de nuestros derechos, pero también de nuestra debilidad material y de nuestra vulnerabilidad ${ }^{74}$.

74 Antoni Rovira i Virgili, Catalunya i Espanya, "Catalunya», Buenos Aires, 1939. 